\title{
Migración de léxico regional al español americano. La crónica de fray Bernardino de Sahagún
}

\author{
Teresa Bastardín Candón* \\ Universidad de Cádiz, España
}

\begin{abstract}
Resumen
Tomando como fuente la Historia general de las cosas de Nueva España, de fray Bernardino de Sahagún, abordamos el análisis de las particularidades léxicas más relevantes en la obra de este fraile. Por una parte, se muestran las voces, de carácter regional, propias de su modalidad dialectal leonesa; por otra parte, se recogen otros vocablos de adscripción geográfica concreta, particularmente meridionalismos y otros términos del norte peninsular, como muestra del grado de nivelación y de criollización léxica en la lengua del franciscano, que se corrobora en la asimilación y adaptación de muchas de estas voces en el dialecto americano. Insistimos en la comprobación del uso histórico de estos vocablos y acepciones, a partir de su seguimiento diacrónico en los documentos y obras lexicográficas de distintas épocas, y en el análisis de los mecanismos discursivos que acompañan a los escritos de cualquier periodo, de acuerdo con la tipología textual de la obra, y con su finalidad etnográfica.
\end{abstract}

Palabras clave: variedades léxicas, español de América, léxico colonial.

* Para correspondencia, dirigirse a: Teresa Bastardín Candón (teresa.bastardin@uca. es), Departamento de Filología, Facultad de Filosofía y Letras, Universidad de Cádiz, Avda. Gómez Ulla, 1, 11003 Cádiz, España. 


\title{
Migration of regional lexicon to the American Spanish: The CHRONicle of Fray Bernardino de Sahagún
}

\begin{abstract}
Based on the Historia general de las cosas de Nueva España, by fray Bernardino de Sahagún, we tackle the analysis of the lexical particularities more notable in the work of this friar. On the one hand, we show the voices, of regional character, characteristic of his leonese dialectal modality; on the other hand, we collect other words of concrete geographic ascription, particularly andalusian voices and other north peninsular terms, as a sample of the degree of levelling and of the creole character in the language of the franciscan, that corroborates in the assimilation and adaptation of many of these voices in the American dialect. We insist on the verification of the historical use of these words and meanings, from their diachronic follow-up in the documents and lexicographical works of various periods, and in the analysis of the discursive mechanisms that accompany the writings of any period, in accordance with the textual typology of the work, and with his ethnographic purpose.
\end{abstract}

Key words: lexical varieties, Spanish of America, colonial lexicon.

Recibido: 30/08/11.

Aceptado: 12/10/11.

\section{INTRODUCCIÓN}

El estudio de la aportación lingüística regional en la configuración del español americano cuenta con una larga tradición en los trabajos dialectológicos sobre la modalidad americana, con una importante presencia de la tesis andalucista, que defiende la impronta meridional en la conformación y definición del nuevo dialecto, sin olvidar la participación de otros grupos de pobladores en el proceso de coinización americano, con la contribución de algunas de las particularidades lingüísticas propias de otros dominios dialectales hispánicos ${ }^{1}$. Estas particularidades propias de cada región y

\footnotetext{
1 Las noticias sobre las diferencias que se aprecian en el español que traen los distintos colonos, según su procedencia regional, son abundantes desde el inicio de la colonia, y reflejan
} 
grupo social afloran en las fuentes históricas y documentales de la época y son especialmente abundantes en el terreno léxico. De ello dan buena cuenta los escritores a uno y otro lado del Atlántico, con registros que muestran, en el caso americano, el cumplimiento de una criollización lingüística que se efectúa como recurso de adaptación a la nueva realidad indiana ${ }^{2}$, y con datos que recogen, en ocasiones, esta diversificación dialectal y su contraste americano ${ }^{3}$. Junto a los antiguos usos medievales, privativos de cada dominio lingüístico, son muchos los cronistas que atestiguan la progresiva dialectalización de términos en otro tiempo generales, las nuevas creaciones semánticas de origen diatópico que van surgiendo, así como la presencia de dialectalismos, de distinta procedencia, que los procesos de coinización han ido implantando en los distintos territorios peninsulares. Entre estos autores destaca, además, por su asunción del hecho americano, fray Bernadino de Sahagún. Su adscripción geográfica permite descubrir los usos propios de su modalidad leonesa, sus más de sesenta años en el Nuevo Mundo, y la asimilación e identificación con las nuevas tierras, actitud compartida por los miembros de su Orden (Frago 1999: 20), se reflejan asimismo en su acervo lingüístico, con la constatación de numerosos americanismos léxicos, bien procedentes del fondo patrimonial común, bien tomados de las lenguas indígenas, sin que puedan soslayarse otros originarios de las distintas variedades regionales peninsulares ${ }^{4}$. El análisis léxico de su obra se justifica, por tanto, por la procedencia regional leonesa de su autor, y por su cronología, a fines del quinientos, cuando el español americano ha adquirido algunas de sus características más relevantes. Las variantes lingüísticas que muestra exigen asimismo atender a los usos discursivos y pragmáticos que

el panorama peninsular del español en la época que nos ocupa, con una diversidad lingüística regional que se establece como resultado histórico del desarrollo y expansión de nuestra lengua en los territorios reconquistados (Frago 1999).

2 Considera Frago (1994: 69) que este proceso de criollización léxica debía de estar muy consolidado en los primeros decenios del siglo XVII, como demuestra el registro de americanismos léxicos en la obra de varios autores, entre los que se encuentra fray Bernardino de Sahagún.

3 Como las citas que recoge Frago (1994: 68) en las obras de Fernández de Oviedo y de Cieza de León: "fesoles...éstos se hacen acá en América muy bien..., llámanse en Aragón judías y en mi tierra arbejas luengas" (Fernández de Oviedo); "y habían hecho algunas chozas que acá llamamos ranchos, en que estaban para se guarecer del agua", "los españoles, sin perder la virtud de su esfuerzo, hicieron como mejor pudieron ranchos, que llamamos acá a las chozas para guarecerse de las aguas" (Cieza de León).

4 Un acercamiento a los usos lingüísticos en la obra del franciscano la encontramos en Frago (1994, 1995) y Franco Figueroa (2001). Sobre la adaptación y la asunción del léxico indígena en la lengua de fray Bernardino puede verse Bastardín Candón (2005). 
las condicionan, de acuerdo con la finalidad descriptiva e informativa de su crónica y con su formación humanística ${ }^{5}$.

\section{TESTIMONIOS REGIONALES EN LA HISTORIA}

La conciencia de diferenciación dialectal, que se documenta en otros autores de la época, está presente, igualmente, en el franciscano, como atestiguan sus continuas referencias contextuales ${ }^{6}$, aunque no siempre sea posible precisar diacrónicamente el carácter más restringido de algunos de estos términos ${ }^{7}$ :

a la yerua que comen los cauallos en eSta ciudad de México llaman caltolli, házeSe en el agua, eS triangulada. En algunas partes de CaStilla Se llama carrizo (L. XI, f. 335r.).

ay vnas aves blancas que se llaman aztatl o teuaztatl, en algunas partes en España se llaman dorales y acá las llaman garçotas blancas los españoles (L. XI, f. 182r.).

En fray Bernardino, como en cualquier emigrado a Indias, el recuerdo de sus tierras está presente en sus evocaciones y en su lengua. Las constantes alusiones a su lugar de origen, con referencias que constatan su procedencia leonesa, muestran, junto a la noticia etnográfica, el registro de unos términos de clara adscripción diátopica (Frago 1995):

no lleuauan aquel compás de los areytos, sino el compas de las danças de Castilla la Vieja, que uan vnos trauados de otros y culebreando (L. II, f. 110v.).

5 Sobre este aspecto de la investigación textual pueden verse Oesterreicher (2004). Sobre los usos discursivos en la obra de fray Bernardino, con especial atención a la presencia de un vocabulario más envejecido, frente a otras variantes más innovadora véase Bastardín Candón (2010).

6 Citamos a partir de la edición facsímil de la Historia general de las cosas de Nueva España (Sahagún 1979), con indicación del libro y del folio.

7 Como sucede con las voces que recogemos en estas citas: carrizo, de la que los diccionarios consultados no traen noticias sobre una extensión diatópica contrastiva, aunque Corominas comenta que la misma forma se halla en portugués, y en Asturias, como nombre de un pajarillo; o doral, que Autoridades, sin referencia geográfica precisa, recoge como sinónimo de papamoscas. 
y traýan en las manos vnas sonajas, con que hazen vn son al propósito del cantar. Son a la manera de trebejos o trebesinos con que hazen callar a los njños quando lloran. Vsanse en los Campos (L. I, f. 23r.).

lleuauan en la cabeça pueStos vnos capillejos compuestos, en lugar de flores, con mahíz tostado, que ellos llaman momochitl, que cada grano es como vna flor blanqujSsima. Estos capillejos eran a la manera que los capillejos de flores que vsan las moças en Campos por mayo (L. II, f. 91r.) .

Vnos gusanos que en CaStilla la Vieja se llaman carralexas, que se crían en las vinas, llámanlas tlalxiqujpilli, son muy ponçoñosas (L. XI, f. $248 v.)^{8}$

\section{LAS VARIANTES FORMALES}

La coexistencia de normas en la lengua de estos emigrados tiene su reflejo en el léxico sahaguntino con la presencia de variantes formales que recuerdan su procedencia norteña. Términos como añuzgar: "quando comjan o beujan añuzcáuanse con la comjda o beujda que no la podían tragar" (L. I, f.25v.) ${ }^{9}$; bilma: "echáuanlos vna bilma en toda la cabeça con resina y plumas de gallina blanca" (L. II, f. 154r.), de uso americano confirmado ${ }^{10}$; bocezar: "quando Se leuanta el borracho, tiene la cara hinchada y disforme y no parece perSona, anda Siempre bozezando" (L. IV, f. 254r.), forma que se oye en Asturias, Cáceres y Mérida, y era frecuente en textos antiguos ${ }^{11}$; ceñilgo: "vnus bledos que Son como cenjzos o cenjlcos de España" (L. XI, f. 402v.) 12; chamarra: "traýa vna manera de chamarra hecha de plumas amarillas" (L. VIII, f. 270v.) ${ }^{13}$; chiflo: "yuan tañedo caracoles marinos y

\footnotetext{
8 No encontramos datos lexicográficos sobre el uso dialectal de la voz. La Academia la incluye en 1783 , con uso general y conocido.

9 El DCECH, s. v. añusgar, comenta que esta variante solo se localiza en tierras salmantinas. Véanse Frago (1994: 69, 1999: 19) y Franco Figueroa (2001).

10 El DCECH, s. v. bizma, comenta la extensión de la voz en América. Como americanismo la recogen Moliner, con imputación a Chile, Cuba, y México, además de registrar su uso salmantino; Santamaría y Neves. Pueden verse, además, Frago (1994: 69, 1998: 85, 1999: 18) y Franco Figueroa (2001).

${ }_{11}$ DCECH, s. v. bostezar, desde el siglo XIII hasta el XVII.

12 El DCECH, s. v. cenizo, recoge esta forma leonesa.

13 Una forma que ya registra Covarrubias. Sobre su uso en América, con nuevas acepciones, basta con consultar los diccionarios generales de americanismos.
} 
vnos chiflos hechos de barro cozido" (L. II, f.94r.) ${ }^{14}$; gorolloso "que tiene pellas': "el que trata en vender papel [...] también vende el de Castilla, el qual es blanco o rezio, delgado, ancho y largo, o gordo o grueSo, malhecho, gorolloso, pudrido" (L. X, f. 58v. $)^{15}$; llogar 'aporcar': "el buen labrador [...] trabaja mucho en Su officio, conviene a Saber, en romper la tierra, cauar, deSeruar [...], acohombrar o llogar la tierra a lo nacido, qujtar el ballico" (L. X, f. 30r.), una forma que no se registra en los diccionarios generales, pero que podría estar relacionada con el étimo locare 'poner, colocar', con palatalización leonesa de la 1- ${ }^{16}$; redruejo 'fruto tardío y poco desarrollado': "todas las coSas aprouechan, las hojas de mahíz y las cañas y las camjsas de las maçorcas y los redroejos del mahíz" (L. IV, f. 314r.); "los tamales hechos de los redruejos" (L. X, f. 52v. ${ }^{17}$; trenchado 'trenzado': "traýan también el cabello largo, crecido, trenchado, y no Se traSqujlauan" (L. X, f. 126r. $)^{18}$, confirman la impronta occidental de este trasvase léxico. Con la forma cuchar, conservada hasta hoy en tierras leonesas, puede ponerse en relación el término acucharrar: "dezían también que si alguno se le secaua la mano o el pie o temblaua o se le acucharraua la mano o el pie [...] todo esto dezían que acontecía porque estos dioses de que aquj se trata se aujan enojado contra él" (L. I, f. 34r. ${ }^{19}$, que no documentamos; y, más cercana a

14 El DCECH, s. v. silbar, recoge como asturiano chifla 'especie de flauta de corteza de árboles', y Terreros confirma el uso de chiflo 'silbato', en algunas partes. Véanse también Frago (1994: 69, 1999: 19), y Franco Figueroa (2001). En América, es abundante el empleo de algunas voces emparentadas, como chifle, chiflón y chiflar, según recogen los diccionarios generales y de americanismos.

15 El DCECH, s. v. orujo, registra la variante dialectal de procedencia leonesa, y hoy general, gorullo o gurullo, con documentación de 1607. La forma gorullo se recoge en el diccionario de Terreros y en el académico, también en su variante gurullo. Moliner considera la primera no usual. Véase Franco Figueroa (2001).

16 El DCECH, s. v. loguer, la registra con los sentidos de 'alquilar', 'ponerse a sueldo de alguien', como catalanismo. La forma logar es 'pagar a una mujer por su cuerpo', ya en el Apolonio, y 'contratar un obrero', en fuero aragonés de 1530 y en Torres Naharro. También recoge allugáse 'acomodarse al servicio de otro' como asturiano, y alugar 'alquilar', en portugués y gallego, pero no registra el sentido.

17 La variante diptongada, que también recogen los diccionarios generales de la Academia y de Moliner, es leonesa, y se registra, en su forma redrueyo, en documento leonés de 1253, según los datos del $D C E C H$, s. v. arredro. La forma redrojo, que Moliner considera no usual, tiene gran vitalidad en América, con nuevos sentidos como 'guiñapo, andrajo', 'persona despreciable', en México, 'sobrante, resto' en Argentina, 'trebejos', y con nuevas creaciones como redrojear 'registrar, rebuscar', en Yucatán, según los datos de Santamaría, Morínigo y Neves.

18 Las obras lexicográficas consultadas no registran esta forma. El CORDE [27-07-2011] solo la registra en la obra de nuestro fraile.

$19 D C E C H$, s. v. cuchara. Véase Franco Figueroa (2001). 
la antigua voz gallega montesyñas parece la forma monciña, que se registra en la obra: "ay muchas ánSeres monciñas que se llaman tlalalacatl" (L. XI, f. $180 \mathrm{v}.)^{20}$. Carece de información lexicográfica, sin embargo, la variante azcadillar o azcadilar 'zascandilear', de empleo recurrente en la obra: "ýuase azcadilando y cayendo" (L. II, f. 108v.); "andan azcadillando con flaqueza, no pudiendo andar" (L. VI, f. 9r.), y probable filiación leonesa (Franco Figueroa 2001) ${ }^{21}$. No faltan en la lengua del franciscano formas que puedan adscribirse hoy al oriente peninsular. Así, la variante altoaragonesa soflar, que recoge el DCECH, s. v. soplar: "el viento començó a suflar o ventear reziamente" (L. VII, f. 232v.), o la norteña mochila, como muchila: "no ay en el mundo Soldados y peleadores que no tengan necesidad de lleuar Su muchila" (L. VI, f. 77r.), una variante que se oye asimismo en el alto aragonés ${ }^{22}$.

\section{LOS MECANISMOS MORFOLÓGICOS}

Tampoco es ajeno a esta diferenciación diatópica el empleo de los recursos morfológicos, responsables de no pocos regionalismos. Si a su origen leonés puede responder la preferencia por la forma trípoda: "los papeles con que aujan de morir no los lleuauan veStidos, más lleuáuanselos vno delante puestos en vna trípoda, que era vn globo que tenja tres pies, sobre que eStaua, sería medio estado de alta esta trípoda sobre el globo" (L. II, f. 153v.), con cambio de género; o el derivado alberque: "se bañauan en vn alberque por hazer penjtencia" (L. VIII, f. 296r.) ${ }^{23}$, una mayor seguridad podemos tener

20 Los diccionarios generales de la lengua solo recogen montiña, con el mismo sentido.

21 De mayor tradición en el idioma, es lusismo, con posible extensión leonesa, la voz aferrar: "dízeSe que el que aSía a eSta fantaSma, con dificultad, podía aferrar con ella" (L. V, f. 336r.), aunque ya Autoridades registra el sentido general de 'agarrar'. El DCECH, s. v. hierro, lo considera término tomado del catalán, y recuerda su origen naútico, muy usual desde el siglo XIV. Todavía Covarrubias, s. v. hierro, lo define como 'asir fuertemente con el hierro'. Para su origen portugues, véase Frago (1999: 142, 158).

22 También en México, Nicaragua, Guatemala, Colombia y Chile, según el DCECH.

23 La Academia registra trípoda desde Autoridades hasta 1803, como variante de tripode. El DCECH no lo recoge, aunque el CORDE [27-07-2011] trae tres contextos más, además del registro sahaguntino, en las obras de Enrique de Villena (1427-1428), Juan de Pineda (1589) y el Duque de Estrada (1607-1645). Las noticias que encontramos para el término alberque se encuentran en el $D C E C H$, s. v. alberca, como derivado. Está ausente, sin embargo en las 
en formas como emprestar: "su officio es también emprestar dineros y pedir más por ellos” (L. X, f. 29v.), voz rechazada por Valdés (2003 [1737]: 191), que la cosidera grosera, y es portuguesismo documentado en hablas andaluzas ya en el medievo (Frago 1999: 160), o achocar 'descalabrar': "començó el dicho nigromántico a matar a los dichos tultecas, achocándolos con vna coa" (L. III, f. 217v.), que tiene uso andaluz en Autoridades, y con esta acepción se documenta en Torres Naharro ${ }^{24}$. La misma recurrencia a los usos propios se observa en la sufijación apreciativa, con el diminutivo -ino, de clara adscripción leonesa, que aparece en formas como trebesino, ya citada, y que, tal vez, haya que poner en relación con la voz tagarno: "vende también xara seca y las pencas de maguey, y las cañas secas y los tagarnos" (L. X, f. 61v.), sin registro lexicográfico en las fuentes consultadas, a partir de una reinterpretación de la voz no derivada tagarnina ${ }^{25}$. La alternancia entre los prefijos des- y es-, y el cambio en otras formaciones, no ajena a otros dialectos hispánicos ${ }^{26}$, se encuentran en escogollarse 'sacudirse': "comjençen ya las avezillas de vuestro pueblo a cantar y a eScogollarse al sol" (L. VI, f. $7 \mathrm{v}.)^{27}$; esfriarse: "dezían que Si algún melliço eStaua cerca del baño quando le calentauan aunque eStuujeSse muy caliente le haría esfriarSe" (Ap. L. V, f. $353 \mathrm{v}$.), de origen portugués, según el $D C E C H^{28}$; espelucar y espelucado: "de cada esqujna qujta vn poco de algodón, y los capullos o cascos vacíalos e hinche tupiéndolos de otro algodón o espelucándolos con aguja, sutilmente, para que parezcan llenos" (L. X, f. 56v.); "cortáuanle los cabellos como a cuextecatl, desiguales y malcortados y espelucados y crenchados" (L. IX, f. $362 \mathrm{v}$.), de amplio uso americano ${ }^{29}$, junto a respelocado: "ay vna aue que Se llama poxaquatl [...] tiene las plumas respelocadas" (L. XI, f. 202r.) ) $^{30}$ y probablemente en escarrapuzar y escarrapuzado, con el sentido de 'erizar': "en lugar de peynarse, escarrapuçáuanse los cabellos hazia arriba por parecer

obras de Covarrubias, Terreros y en Autoridades, aunque la Academia la incluye en 1933. Moliner, la registra como voz no usual. Véase Franco Figueroa (2001).

24 La vigencia de estas voces en el español de América se constata en los diccionarios generales de americanismos que consideran la primera de uso panamericano, con el mismo sentido, y la segunda con acotación a distintos países.

25 No obstante, puede tratarse, con bastante probabilidad, de un término de uso más especializado. El CORDE trae un registro documental del término, en la obra botánica Plantas medicinales. El Dioscórides Renovado, de 1962.

26 Algunos de ellos presentan documentación lexicográfica andaluza.

27 El TLHA confirma su uso en Andalucía con el sentido propio de descogollar.

$28 D C E C H$, s. v. frío. Moliner la recoge como voz antigua.

29 Confirmado en el diccionario académico, que también apunta su uso andaluz, y en los generales de americanismos. El TLHA confirma su empleo en toda Andalucía.

30 Los diccionarios solo registran respeluzar, con el mismo sentido. 
espantables" (Ap. L. III, f. 234r.); "vn poco largos los cabellos y todo lo delantero de la cabeça escarrapoçados hazia arriba" (L. II, f. 107r.), que no se encuentra en las obras lexicográficas consultadas ${ }^{31}$.

\section{LAS ALTERNANCIAS LÉXICAS}

No obstante, si los términos comentados son resultado de su propia competencia lingüística, como muestra de los usos dialectales asumidos, el bagaje léxico del franciscano se amplía con voces de uso general y da cuenta explícita del carácter más regional y restringido de algunos términos, con el registro de coordinaciones y alternancias en los que la conciencia de diversificación léxica parece incuestionable ${ }^{32}$. Los contextos, en este sentido, son abundantes. Así la que hemos registrado para la voz llogar, ya comentada: "acohombrar o llogar la tierra a lo nacido" (L. X, f. 30r.); y otras para términos como lapa: "lapa de monte o Sobrecejo" (L. XI, f. $385 \mathrm{v}$.), de poco arraigo en castellano y abundante documentación leonesa y portuguesa ${ }^{33}$; carrasco: "ay también vnos robles o carrascos muy rezios" (L. XI, f. 265v.), portuguesa en esta acepción, aunque como derivado de carrasca, se documenta en Nebrija, y es forma frecuente en los siglos XVI y XVII ${ }^{34}$; cenizo: "vnos tamales [...] hechos de bledos o cenizos" (L. II, f.

31 Véanse Frago (1999: 19) y Franco Figueroa (2001).

32 Esta consideración explica el uso de alhóndiga y troje como variantes del significado 'granero': "de las troxes o alhóndigas" (L. VIII, f. 278v.). Ambos términos, tildados hoy día de arcaísmos en la Península, pero de amplio uso y vitalidad en zonas regionales meridionales e hispanoamericanas, reflejan empleos diferentes, con un carácter más administrativo y público de alhóndiga, hoy presente en zonas andaluzas y mexicanas, especialmente con el derivado alhondigaje (Santamaría y Neves), y con un matiz más general la voz troje, con sus variantes, troj, troja.

33 Según los datos del $D C E C H$, s. v. lapa 4. El término no se registra en Covarrubias, Autoridades ni Terreros, con este significado, aunque sí la trae Moliner, como voz no usual. Entre los sentidos americanos que pueden relacionarse con esta acepción se encuentran 'calabaza partida por la mitad que se utiliza como fuente', en Chile y Perú, o 'sombrero grande, achatado de copa', en Ecuador y Argentina, según los diccionarios generales de americanismos.

34 Según los datos del DCECH, s. v. carrasca. Autoridades considera que la forma carrasco es más común en Castilla. El sentido de 'extensión grande de terreno cubierta de vegetación leñosa' es americanismo general, que ya recoge el diccionario académico. 
$78 \mathrm{v}$.), también con fonetismo leonés, como hemos visto ${ }^{35}$; cillero: "entrauan en los cilleros y bodegas" (L. IV, f. 302r.), voz propia de Castilla, según Autoridades; correo 'mensajero': "los correos o mensajeros que van muy depriesa suelen beuer esta agua" (L. X, f. 107v.), de origen catalán ${ }^{36}$; páramo: "prosigujeron su camjno por los llanos o páramos para descubrir tierras" (L. X, f. 148r.), occidentalismo ampliamente documentado en la modalidad americana ${ }^{37}$; pega: "es tamaña como vna vrraca o pega de España" (L. XI, f. 173v.), que también presenta una documentación histórica preferente en zonas del oeste peninsular ${ }^{38}$; collera: "les qujtauan las priSiones o colleras con que eStauan preSos" (L. IV, f. 266v.), con uso americano, según todos los diccionarios generales de americanismos; puchas y poleada: "todos hazían vna manera de puchas o poleadas" (L. II, f. 59v.), de poca documentación lexicográfica la primera, y menor extensión norteña la segunda ${ }^{39}$; brotón: "eres probén y brotón de tus abuelos y antepaSsados" (L. IV, f. 307r.), de uso antiguo ${ }^{40}$; plancha y carrera "viga cargadera', "a la plancha o carrera de madero llaman elquauhiotl" (L. XI, f. 271r.), con ampliación significativa de la primera, tanto desde una perspectiva sociolingüística como geográfica ${ }^{41}$; granzón: "los eScobajos o grançones del mahíz, que Son

35 Véanse Frago (1999: 19) y Franco Figueroa (2001). Como nombre de varias plantas indígenas se recoge en distintos lugares de América.

36 El $D C E C H$ recuerda que en esta acepción no se encuentra, a excepción de en Nebrija, hasta finales del siglo XVI.

37 Con acepciones como 'llovizna' en Colombia y Ecuador, según el diccionario académico, 'paraje alto, yermo y de clima frío' en la zona andina. Véase Franco Figueroa (2001).

38 El DCECH, s. v. picaza, lo considera vocablo portugués. Covarrubias confirma la sinonimia con los términos picaza y urraca. La documentación histórica la registra con abundancia en autores del occidente peninsular, como Torres Naharro, Correas o el propio Sahagún, y hoy es voz exclusiva del oeste peninsular.

39 Según el $D C E C H$, aunque comenta que siempre ha sido admitida por la Academia. La voz puchas tiene menos documentación histórica, aunque se registra en Nebrija y Lope de Rueda, según los datos del $D C E C H$, s. v. puches, que comenta, además, su uso hoy en Bilbao como 'cuajada'. La forma puches es, sin embargo, la que recogen Covarrubias, Autoridades y Terreros. También registran esta única forma Moliner y el diccionario académico actual. Su uso americano queda atestiguado en los diccionarios de americanismos, con sentidos como 'pan en forma de rosquilla', de poco uso en México, según Santamaría, y 'medida para granos' y 'porción pequeña de algo' en Colombia, según Neves.

40 Los diccionarios generales de la lengua, desde Autoridades y Terreros, coinciden en que se trata de un arcaísmo léxico. Probablemente tuviese ya en este periodo un uso regional, según podemos interpretar de los datos de Covarrubias, que atestigua su alternancia con el término redrojo y la variante bretón. Hoy su uso se confirma en las hablas andaluzas, según el TLHA.

${ }^{41}$ El sentido marinero de plancha 'tablón con tojinos o travesaños clavados de trecho en trecho, que se ponen como puente entre tierra y una embarcación' aparece recogido en el $D R A E$ y en Moliner. El sentido de carrera 'viga' se incluye en el diccionario académico 
aquellas maçorqujllas que quedan después de deSgranada el mahíz" (Ap. L. V, f. 350v.), probablemente, voz más asimilada a la zona leonesa (Franco Figueroa, 2001), y mostolilla: "deSte anjmalejo que Se llama comadreia o mostolilla Se eSpantauan" (L. V, f. 339r.), de origen leonés, según el DCECH, s. v. mustela.

La alternancia de voces a lo largo de la obra refleja idéntica situación. Así, junto al general pegote o parche: "vn pegote de ocotzote" (L. X, f. 111v.), "Se echan los poluos en la laga pudrida o echa parche" (L. XI, f. 298v.), se registra la voz parcho, hoy americana: "se pondrá vn parcho para acabar de sanar" (L. X, f. 115r.) ${ }^{42}$; la forma bizma: "echar cierta bizma de ocutzote" (L. $\mathrm{X}, \mathrm{f} .103 \mathrm{r}$.), y la más numerosa bilma, con el ya comentado fonetismo leonés. La variación se observa, también, entre el occidentalismo sobrado: "caSas o

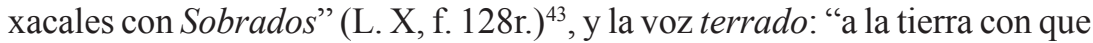
hazen los tlapancos [...] llámanla tlapantlalli, que qujere dezir de terrados" (L. XI, f. 381r.), que Corominas considera término desusado y sustituido por azotea, salvo provincialmente. También esta última se documenta en nuestro corpus, y hay que recordar que ya Autoridades la considera como vocablo más común de Andalucía y otras provincias ${ }^{44}$ : "don Hernando Cortés SubioSe encima de vna açotea de vna casa del barrio de Amaxac" (L. XII, f. 487r.). Asimismo, la voz arrendar 'remedar, imitar', variante de la antigua forma portuguesa (a)rremedar: "eSta aue canta y habla y parla qualqujer lengua que le enseñan, arienta a los otros anjmales, responde diziendo lo que dizen, cantando lo que le cantan" (L. XI, f. 177v. $)^{45}$, convive con contrahacer: "començauan a bozear y a gritar y a contra hazer las aues del agua" (L. II, f. 94v.), y con la antigua retraer: "eSta cortesía que Se hazía y esta manera de criança retraýa la manera de tomar y tirar los dardos que vsauan tirar en la guerra" (L. IX, f. 336v.).

en 1852. El TLHA confirma su uso en Granada. Puede tratarse, no obstante, de una voz de ámbito especializado.

42 De manera general, es voz usada en la zona caribeña. El diccionario académico la imputa a Puerto Rico, y Morínigo a Colombia y Venezuela. Neves la extiende a todas las Antillas y Venezuela.

43 Morínigo recoge su uso en Paraguay, como 'cobertizo de piso alto para airear los productos', y en Argentina, con el sentido de 'especie de cornisa que sirve de vasar'. La variante soberado es americanismo general con el significado de 'desván', y tiene un uso específico como 'piso de la casa', en Puerto Rico, y como 'entablado para dormir o para colocar objetos', en la República Dominicana y Venezuela, según los datos de Morínigo y de Neves. Véase Frago (1998), que la considera voz del noroeste peninsular, implantada en Andalucía.

44 Nótese que Covarrubias, s. v. terrados, observa "por otro nombre azotea", y que, s. v. sobrado, igualmente considera "comúnmente desvanes o azoteas".

45 Según el $D C E C H$, s. v. imagen. Terreros considera ya la voz de poco empleo. 


\section{LÉXICO PENINSULAR NORTEÑO}

Sin las variaciones y alternancias comentadas, sino como formas léxicas propias de su idiolecto, se documentan en la obra otros términos de ascendencia norteña. De origen occidental histórico comprobado y extensión americana, son los términos ciénaga, y su variante ciénega, hoy forma vulgar en toda América, según el DCECH: "ranas de cieno, y críanse en las ciénagas" (L. XI, f. 219v.); "házeSe en las ciénegas" (L. XI, f. 310r.) y frijol: "ponjanles, en lugar de ojos, vnos frisoles negros" (L. I, f.33r.), de origen gallego portugués, y empleo más restringido, según Autoridades, que lo considera usual en algunas partes ${ }^{47}$, y prieto: "tiene la cabeça grande, las orejas son pequeñas, el hoçico grueSso y carnoso y corto y de color prieto" (L. XI, f. 156r. $)^{48}$. De probable ascendencia noroccidental, pero con amplio uso andaluz y americano es frangollado: "el que es mal tratante en eSto, la harina que vende es mal molida ofrancolada" (L. X, f. 54v. $)^{49}$. La documentación histórica apoya igualmente los dialectalismos enterriarse y enterriado: "es furiosa, envidiosa, enójase, enterríase, embraueçase" (L. $\mathrm{X}$, f. 8r.), "la nuera mal acondicionada es responSona y enterriada" (L. X, f. 8r.), una forma ausente en los diccionarios generales de la lengua, salvo en Moliner, que considera la primera de uso salmantino, y se encuentra en las obras de Juan del Encina, Lucas Fernández, y Sánchez de Badajoz ${ }^{50}$. Como voz asturiana recoge el DCECH, s. v. escupir, el vocablo escupida: "y el hecharle eScupita o vn poco de pulcre encima dezían que eSto era emborracharla" (L. V, f. 340r.), que se registra para México, Cuba y Argentina en Santamaría, EC y EA. Occidentalismos son asimismo

46 DCECH, s. v. cieno. El uso mexicano de esta variante la recoge Santamaría (1983) y Moreno de Alba (1992: 175). Véase Frago (1999: 45).

$47 \mathrm{DCECH}$, comenta el uso americano, que confirma el diccionario académico y los generales de americanismos, con abundante fraseología.

$48 D C E C H$, s. v. apretar, la acepción antigua 'moreno', 'negro', doc. 1330, inventario aragonés, hoy subsiste en Asturias y otras partes; Covarrubias, lo considera vocablo castellano antiguo, muy usado en Toledo. Su empleo en América se refiere en el diccionario académico, con los sentidos 'de raza negra', en Cuba, 'de piel morena', en México, y se constata en los diccionarios generales de americanismos, en Morínigo y Santamaria, para su uso mexicano, y en $E C$. Véanse Frago (1999: 18, 19, 237, n.84), con documentación de fray Toribio de Benavente y fray Bernardino de Sahagún; y Franco Figueroa (2001).

$49 \mathrm{DCECH}$, con variantes como frangollo, frangollón, frangollador. El diccionario académico, también con marcación diatópica. Para estos y otros derivados, así como para las distintas acepciones de la voz pueden verse los diccionarios generales de americanismos.

50 DCECH, s. v. tirria. CORDE [27-07-2011]. 
vaquiruela: "ay vnos lagartillos del agua, [...] eStos se crían también en los lugares húmedos, pienso es vaqueruela de Castilla" (L. XI, f. 228r.), que el diccionario académico considera de uso salmantino, y Moliner, en la forma vaquigüela; y zuñir: "van tras ella las moscas, zumbando o zunjendo" (L. XI, f. 239r.), que el $D C E C H$, s. v. zumbar, considera voz leonesa. El término desainarse 'desangrarse': "también mata porque se desaýna el que lo beue o lo come" (L. VI, f. 109r.), es empleado en Salamanca, Palencia y el Guadarrama, y la Academia no lo incluye hasta $1970^{51}$. Más general es el término embarazar, de origen leonés o portugués: "no querría embaraçaros en vueStras ocupaciones" (L. VI, f. 164r. $)^{52}$. Como voz aragonesa podemos citar verdasca: "tomó vna verdasca y començo de herir a la culebra" (L. XI, f. 162v.), según Terreros ${ }^{53}$; y, con mayor dificultad de delimitación, el término buro: "los perros desta tierra [...] son de diuerSas colores, ay vnos negros, otros blancos, otros cenjçientos, otros buros, otros castaños escuros, otros morenos, otros pardos, otros manchados" (L. XI, f. 170v.), con presencia en hablas leonesas, pero también aragonesas con el significado 'arcilla', si bien, los contextos seleccionados presentan una clara relación con el sentido 'color acanelado', que el DCECH, s. v. buriel, registra en el asturiano buru.

\section{LA IMPRONTA MERIDIONAL}

Si bien los occidentalismos responden, incuestionablemente, a su modismo dialectal norteño, el proceso inevitable de acriollamiento explica la adaptación paulatina del léxico patrimonial en el Nuevo Mundo y justifica, al mismo tiempo, el empleo de un vocabulario con variantes que recuerdan otras regiones peninsulares. Es el caso de voces con evidente filiación meridional como agro: "no se an de comer tortillas calientes nj cosa agra"

51 DCECH, s. v. saín, y s. v. sangre, que añade una forma dialectal catalana sainar, de uso en hablas de Castilla la Vieja y León, y en refranes aragoneses del siglo XIV. Neves recoge su uso en Cuba como 'debilitar'.

52 Según el $D C E C H$, y el diccionario académico.

53 Aunque el DCECH, s. v. verde, registra la forma asturiana vardasca El CORDE [2707-2011] recoge esta variante en la obra de Bartolomé de las Casas, con la coordinación "una vara o vardasca". 
(L. XI, f. 301v. $)^{54}$, voz de poco uso para Autoridades; candela: "apagada está nuestra candela, fuéSenos nuestra lumbre" (L. VI, f. 42r.), que Terreros considera de empleo andaluz y americano ${ }^{55}$; espadarte: "el primer carácter Se llama cipactli, que qujere dezir vn eSpadarte, que es pez que viue en la mar" (L. IV, f. 244v.); "otros dicen que este era vn ocico de espadarte, que es vn pez marino que tiene vn arma como espada en el ocico, que tiene colmjllos de ambas partes" (L. II, f. 102r.), con aclaración del sentido en estos contextos, y fuerte arraigo, desde antiguo, en el mediodía peninsular (Frago 1994: 70); altabaque: "traýa en las manos vn gran altabaque de madero, lleno de greda blanca" (L. II, f. 126r.), variante que el $D C E C H$, s. v. tabaque, documenta en el Cancionero de Baena, y que Autoridades confirma como de uso andaluz ${ }^{56}$; ponzancón: "donde eStá vn ponzanco profundo y quando crece la laguna crece él y quando mengua la laguna mengua él” (L. XI, f. 384r.) $)^{57}$; o rancho: "y por entonce cesó la pelea, bolujéronse todos a sus rranchos y el día Sigujente tanpoco pelearon" (L. XII, f. $485 \mathrm{v}$. $)^{58}$, por citar algunos de los que se registran en el corpus. La referencia explícita a la variación léxica, en el caso de ostión: "estas conchas son cóncavas y anchas [...] algunas dellas, por de dentro, tienen vn esmalte que representa diuerSas colores, eStas son aquellas en que se hazen las perlas, que por otro nombre se llaman ostiones" (L. XI, f. 216v.), puede probar no solo la preferencia meridional de la voz, sino también su adaptación americana ${ }^{59}$.

No obstante, la delimitación de los usos regionales requiere de la constatación de su empleo privativo tradicional o moderno, así como de su extensión en determinados estratos sociales más o menos populares. $\mathrm{La}$ dificultad en este terreno es notoria, pues el criterio contrastivo que se exige en la determinación de estos dialectalismos se halla sujeto, por un lado, a unas

54 El DCECH, s. v. agrio, considera que fue la forma normal hasta el siglo XVII, y es la que recogen Nebrija y Palencia, pero indica que un literato granadino, en 1601, considera esta voz como usual en Andalucía, frente a agrio, en Castilla.

55 También Autoridades comenta su empleo en Andalucía y otras partes. La vitalidad del término en el español americano se confirma en la abundante fraseología que se registra en cualquier obra lexicográfica general y americana.

56 Frago (1998: 82) recoge tabaque en Vicente Espinel, y opina que debía de ser un vocablo no general, ya en esa época, y que hoy presenta mayor implantación en Andalucía.

57 Los diccionarios generales recogen pozanco 'poza que queda en las orillas de un río al retirarse las aguas'. La forma pozancón es 'especie de cisterna', en Argentina, según el $D C E C H$, s. v. pozo. Para la forma que recogemos véase Frago (1994: 126).

58 El $D C E C H$ reconoce su mayor vitalidad en América y se confirma en los diccionarios de americanismos.

59 El DCECH, s. v. ostra, comenta que la voz se conserva en Andalucía, Cuba, Costa Rica, Argentina y México. Para Covarrubias es vocablo usado corruptamente. 
fuentes lexicográficas, en ocasiones, imprecisas, por otro, a los avances que, en el terreno de la documentación textual y la investigación dialectológica, en general, se vayan realizando ${ }^{60}$. La caracterización y adscripción de algunos de los vocablos que registramos en el corpus se encuentran en esta situación. Ejemplo de ello son aquellas voces que, como variantes fonéticas, perviven hoy dialectamente, términos como la nebrisense cernir frente a cerner: "Sabe bien cernjr la harina y amasarla y Sobarla" (L. X, f. 53v.), doblete léxico que confirma Covarrubias, y que hoy parece conservarse en algunos países americanos y en Canarias, según datos del ALEICan ${ }^{61}$; las variantes empolla: "Son semejantes a las campanjllas o enpollas del agua" (L. XI, f. 358v.); esternudar: "dezían que el que eSternudaua era Señal que alguno dezía mal dél" (Ap. L. V, f. 352v.), e injundia: "la injundia desta culebra es medicinal para la gota" (L. XI, f. 231r.), hoy de uso andaluz y americano, cuyos registros lexicográficos se restringen al académico, en los casos de empolla e injundia, y al Vocabulario de Palencia, en el caso de esternudar 62 ; o la hoy, también andaluza, según la Academia, hiñir: "Sabe bien cernjr la harina y amasarla y Sobarla y hinnjr los panes y leudarlos y hazer tortas" (L. X, f. 54r.). La forma estilla: "deSte madero, hediéndolo, házenlo eStillas y májanlo y rremójanlo en agua" (L. XI, f. 370r.), no se encuentra registrada en los diccionarios generales de la lengua, pero sí la recogen los de americanismos, y no podemos olvidar que existe una forma asturiana estiella ${ }^{63}$. La misma imprecisión encontramos en la voz apregonar: "y mandó a vn pregonero que apregonaSse y llamase a todos los comarcanos de Tulla" (L. III, f. $217 \mathrm{v}$.), variante rara en el DCECH, s. v. pregón, que Autoridades y Terreros dan como anticuada y que el Tesoro confirma como de uso vulgar en toda Andalucía.

60 Sobre la extensión de ciertas voces, hoy consideradas dialectales, en el español de los siglos XIII, XIV y XV puede verse en Buesa Oliver (1990).

${ }^{61}$ El DCECH, s. v. cerner, la considera forma usual en Argentina, México y otros países de América. Santamaría recuerda, además, que se registra en Autoridades, pero no en las ediciones siguientes, hasta la duodécima. Sobre su uso canario, y su posible origen andaluz, puede verse Llorente Maldonado (1984: 286).

62 La voz empolla no se registra en el $D C E C H$. El diccionario académico señala su uso vulgar. Para América se recoge en Santamaría, Morínigo, como vulgarismo en toda América, y Neves, en Colombia y México.La voz esternudar es de uso en México, según el $D C E C H$, s. v. estornudar, si bien Santamaría y Neves la consideran voz antigua. El TLHA confirma su uso en toda Andalucía. Por último, injundia es de empleo en algunas partes de Andalucía, según el TLHA, que la registra en Granada y Almería, y en toda América, según Neves.

63 Según el $D C E C H$, s. v. astilla. Morínigo, con imputación a Antillas y Colombia; Neves, como americanismo, vulgar, también con el sentido 'persona pícara', en Cuba. 
Una menor dificultad presenta la constatación del regionalismo léxico en los casos en los que el fonetismo dialectal aflora en la escritura. Así, de probable filiación meridional es la voz balandrón: "Gran balandrón. ESte refrán Se dize del que Se alarga mucho en dezir bien de sí o de Sus cosas" (L. VI, f. 193r.), cuyo refuerzo nasal no solo es fenómeno ampliamente documentado en hablas del sur peninsular, sino que es variante que se documenta ya en textos históricos americanos y que el diccionario académico confirma para Argentina, Honduras, Perú, Uruguay y Venezuela, y Santamaría para México ${ }^{64}$; el mismo fenómeno se detecta en la variante arronjar: "y luego arronjaua el incenSario con el papel ardiendo hazia el sumidero" (L. II, f. 99r.), considerada andaluza y americana ${ }^{65}$; y explica la forma sombrado 'sobrado': "Calnepanolli, casa con Sombrado" (L. XI, f. 395r.), si bien, en este último caso, puede deberse a un cruce con la forma sombrajo. Para la variante sienso: "hechó el perro por el Sienso todas las tripas y todos los ýgados" (L. VI, f. 141v.); "también come gallinas, chupándolas por el sienso" (L. XI, f. 168r.), sin embargo, hay que recordar que Corominas recoge una forma asturiana cenzo $^{66}$.

\section{REGIONALISMOS SEMÁNTICOS}

El sentido restringido de algunos términos y su empleo preferente en determinadas áreas peninsulares pueden probar, asimismo, el arraigo regional de las voces en cuestión, como sucede con el probable meridionalismo camisa: "atar las maçorcas vna con otra, añudando las camjsillas vna con otra" (L. X, f. 30r.), que, con el sentido 'farfolla', se registra hoy en Andalucía y Canarias ${ }^{67}$; o con el leonesismo horrura: "ay vnas vrroras que se crían Sobre el agua" (L. XI, f. 221r.), de fuerte implantación en tierras salmantinas, con el significado de 'sedimento', 'cieno que dejan los ríos en

${ }^{64}$ El DCECH, s. v. baladrón, comenta su empleo en la Historia del Perú de Gutiérrez de Santa Clara, y en otros americanos.

${ }_{65}$ El DCECH, s. v. arrojar, recuerda que esta variante se encuentra en Sánchez de Badajoz, Mateo Alemán y es usual en otros textos andaluces e hispanoamericanos.

66 El DCECH, s. v. sentar. El CORDE [27-07-2011] la documenta en 1484, en documento notarial, y en 1599, en el Libro de la Peste y en las Instituciones algebristas, de Luis Mercado.

${ }_{67}$ El TLHA, en Cádiz, Huelva, Málaga y Sevilla. Para su probable origen andaluz, y su uso canario véase Llorente Maldonado (1984: 286). 
las crecidas' (Salamanca), según el diccionario académico ${ }^{68}$; la voz escriño: "ponjanle en la cabeça vna corona, a manera de scriño, que venja justa a la cabeça y en lo alto ýuase enSanchando" (L. II, f. 88v.), presenta, ya desde antiguo, el significado 'cascabillo de la bellota', en Zamora y Salamanca, según recogen el $D C E C H$ y la Academia; y recello: "en el pecho y en la cara tiene vn reçello de pelos grandes que le haze espantable" (L. XI, f. 163r.), aparece documentada en el TLHA con la forma recillo 'caracol del pelo', un significado próximo al que registramos, si bien, en este caso, puede tratarse de una forma leonesa, atestiguada por la presencia de la palatal ${ }^{69}$. Asimismo la acepción etimológica de achacarse 'quejarse': "el entenado traujeso y vellaco [...] haze dél graue quando le mandan o achácaSe" (L. $\mathrm{X}, \mathrm{f}$. 9r.), que se documenta en Juan Ruiz, solo parece haberse conservado dialectalmente, y no podemos olvidar que la portuguesa achaque se define en algunos diccionarios como "motivo de queja, acto de quejarse' ${ }^{\text {'70 }}, \mathrm{y}$, apañar: "para hurtar sabe mjll modos, mjente, acecha y horada las caSas, y Sus manos son como garauatos con que apaña lo que puede" (L. X, f. 28v.), con el significado de 'hurtar', que es el que recogemos, es acepción documentada ampliamente en el oeste peninsular, con textos gallegos, portugueses, y una forma pañar, asturiana, según el $D C E C H^{71}$. Del mismo modo, tal vez haya que entender el sentido asturiano de 'racimo', o incluso el de 'madera', para el vocablo piño, según el contexto que registramos: "ay piños en eSta tierra como los de España, házense en ellos piños y piñones" (L. XI, f. 264r.) $)^{72}$. Por último, hay que señalar que el sentido de 'flojo, haragán', 'cobarde' de la voz falso, se emplea en Navarra y Aragón, según el diccionario académico y el de Moliner ${ }^{73}$.

68 Santamaría recoge una forma urrona 'animalillos que se crían sobre las aguas', con documentación de Sahagún. Llorente Maldonado (1984: 302-303) la considera leonesismo conservado hoy en Salamanca, según el diccionario académico; y en Extremadura, en la acepción 'hierbajos que flotan en las riadas'.

69 Los diccionarios generales traen una forma recel 'cobertor o cubierta de tela delgada y listada', a partir del étimo RE CELARE. Tal vez, sea posible aventurar una etimología a partir de la forma RE CILIUM. El CORDE [27-07-2011] solo registra el contexto sahaguntino.

70 Todos los diccionarios consultados, desde Nebrija hasta la edición actual del académico recogen solo la acepción 'acusar'.

71 Este sentido se conserva en América, con mayor presencia, según los diccionarios de americanismos, en México. Véase Frago (1998: 85, 1999: 18, 23), y Franco Figueroa (2001).

$72 D C E C H$, s. v. pino, considera que la acepción 'porción de ganado, tropilla' que se localiza en Chile, Argentina y Bolivia, procede de esta acepción. También la recoge Sala (1982: 297).

73 En Cuba es 'persona que se preocupa poco por mantener a sus amigos', según el diccionario académico y EC, y Sala (1982: 268), que añade 'cobarde' en Chile, 'descuidado con sus obligaciones sociales' en Argentina y Cuba. 


\section{VARIANTES DIACRÓNICAS}

La consideración del regionalismo léxico en su perspectiva histórica resulta más compleja en los casos en los que la repartición geográfica de ciertos fenómenos o de determinadas voces se atiene, de manera exclusiva, a un seguimiento diacrónico de no fácil delimitación. La nómina de voces consideradas arcaicas, pero con pervivencia en áreas dialectales específicas, es, en este sentido, abundante, y requiere de la constatación cronológica que permita su adscripción diatópica en el estado de lengua en cuestión. Es lo que se comprueba con la variante gallego-portuguesa silva 'selva': "es cierto cosa de grande admjration que aya nuestro Señor Dios tantos siglos occultada vna silua de tantas gentes ydólatras" (Pr., f. 2r.), que, aunque no ajena al castellano, fue palabra arcaica o poética desde muy pronto, según afirma el $D C E C H$, s. v. selva, que recuerda que ya Nebrija la considera innovación personal de Juan de Mena; otro tanto puede afirmarse de aterecimiento: "lugar de hambre y de frío y de aterecimjento y donde se baten los dientes vnos con otros" (L. XI, f. 262v.), pues, el verbo aterecer, que se documenta en Nebrija, sigue vivo hoy en Asturias, León, Albacete y partes de Castilla ${ }^{74}$, y es ya forma poco usada para Covarrubias y Autoridades, mientras que Terreros señala su uso castellano; y de cocote: "la vedija de los cabellos que traes en el cocote en señal de cobarde y de hombre para poco" (L. II, f. 82v.), variante que hoy se conserva en el norte peninsular, y en varios países americanos, y que Autoridades y Terreros dan como de poco uso ${ }^{75}$. Con mayor asimilación a la zona meridional encontramos tabardete: "eSta yerua mulida y bebida es contra el tabardete, quando comjença a parecer con vnas pintas como de cardenjllo" (L. XI, f. 303r.), que Autoridades considera menos usado que tabardillo, y no recogen ni Covarrubias ni Terreros, pero que hoy es usado en Andalucía, Puerto Rico y Venezuela ${ }^{76}$, y probablemente la variante torcaza: "ay también en esta tierra palomas que Se llaman tlacavilotl, son como palomas torcaças de Castilla" (L. XI, f. 207r.), que con menor extensión geográfica en esta época, no la registran ni

74 Según el DCECH, s. v. aterir.

$75 D C E C H$, s. v. cogote, la recoge para Aragón, Vizcaya, Santander, León, y también Murcia. En América, es frecuente en Cuba, Santo Domingo, Colombia, etc. EC confirma su uso en Cuba. Frago (1999: 46) señala su arraigo en Aragón. También en el TLHA, en toda Andalucía.

76 El DCECH, s. v. tabardo, la documenta en 1590, Acosta. Además del sentido de 'insolación', se encuentran 'persona molesta', disgusto grande'. 
Autoridades ni Terreros ${ }^{77}$. Una mayor dificultad presenta la consideración regional del uso etimológico del vocablo tamaño: "si por uentura tamañjto como eStá perecerá" (L. VI, f. 136r.); "es tan grande como vna ave que se llama tzanatl, que es tamaña como vna vrraca o pega de España" (L. XI, f. $173 v$.), cuya vigencia en el Siglo de Oro parece atestiguada, si bien, a fines del siglo XVI era tenido por anticuado al menos en algunas regiones y es, precisamente, su pervivencia dialectal la que puede justificar su presencia en amplias áreas hispánicas ${ }^{78}$, como se constata en gran parte de América y en Andalucía, según el TLHA. También la alternancia registrada en el corpus entre los vocablos calcañar y calcaño: "hazer calcañar de çapatos, echar traujllos a los çapatos" (L. X, f. 55v.); "las cotaras que lleuaua eran blancas y los calcaños eran texidos de algodón" (L. II, f. 147r.), apunta en esta dirección, con una distribución regional que se comprueba en el uso hoy leonés de la segunda, considerada antigua y dialectal, según los datos del $D C E C H^{79}$. De posible extensión diatópica, en este momento, parece ser, asimismo, la forma abondar: "floresce y abonda en mj casa donde nací" (L. VI, f. 183r.), que registra Nebrija, y que Valdés (2003 [1737]: 166) rechaza frente a abundar, significativamente en esta acepción se encuentra hoy en León y Salamanca según las fuentes consultadas ${ }^{80}$. Idéntica consideración histórica merece el análisis del fenómeno fonético de la vocalización de consonantes implosivas, pues si es este un rasgo innovador norteño para la época que nos ocupa, las variantes registradas en las soluciones que se adoptan, entre la vocalización y pérdida de la misma, son las responsables de la conservación americana de las voces recaudo 'mensaje', 'conjunto de objetos necesarios para hacer ciertas cosas': "eSte refrán Se dize del que es enviado a alguna menSaiería o con algún recaudo y no buelue con la respueSta" (L. VI, f. 187v.), "a las mugeres dauan los recaudo para que hilaSsen" (L. IX, f. 344r.), y recado 'recaudo': "los captiuos estauan a mucho recado porque no huyesen" (L. II, f. $117 \mathrm{v}$. $)^{81}$. Asimismo, un mayor arraigo en el occidente peninsular parecen haber tenido voces como tocho: "los

\footnotetext{
77 La Academia la incluye en 1803, como anticuada. Su uso en América está atestiguado como nombre genérico de las palomas torcaces, según Santamaría, Morínigo, Neves, y EA.

78 Según los datos del $D C E C H$, que comenta el predomino del sentido absoluto en gran parte de América, desde Cuba hasta Argentina, y el empleo de los intensivos tamañito y tamañazo; aunque el valor etimológico y clásico pervive en el habla popular chilena.

79 Téngase en cuenta, no obstante, que Moreno de Alba (1992: 187) considera que la voz calcañar tiene bastante empleo en México.

80 Ténganse en cuenta, además, las indicaciones del $D C E C H$, s. v. bastar, que señala que, en la acepción 'ser bastante', la voz es considerada por un escritor granadino de 1601 como propia de Andalucía, frente a la castellana bastar, y que la forma bondar 'bastar' pervive hoy en León.

81 Véase, al respecto, Frago (1999: 49, 122, 130, 134).
} 
que eran tochos y son locados reýanse deste negocio" (L. II, f. 112r.), que aparece, además, en frases como a tochas y a necias; "voela como la lechuça, a tochas y a necias, por eSso se llama poxaquatl" (L. XI, f. 202r.) ${ }^{82}$; y otras formas como trasgo: "tiene algún trasgo que le ayuda, dízesSe eSte refrán de aquellos que no parece que hazen nada y eStán ricos" (L. VI, f. 189r. ${ }^{83}$; o tristel: "no Se bebe Sino dase por triStel" (L. XI, f. 299r.) ${ }^{84}$. Preferencia por la forma lumbral, que Autoridades considera de poco uso, en su variante lumbrar: "en llegando a la puerta de la casa, dauan otros golpes en el lumbrar de la mjsma casa" (L. IV, f. 301v.), parece darse en tierras norteñas, a tenor de su empleo hoy en Salamanca ${ }^{85}$. De carácter dialectal puede considerase asimismo rencle y renclera (o rengle y renglera): "ordenáuanse todos en rencle y yuan delante los viejos" (L. II, f. 151r.) "ponjanlos todos por orden en Sus rencleras Sentados" (L. II, f. 60v.), que están ausente, en general, en los clásicos, y faltan en las obras lexicográficas hasta Oudin, aunque aparece, con variantes, en autores teñidos de regionalismos, como Lucas Fernández, Fernández de Oviedo, Gonzalo Pérez, por citar algunos ${ }^{86}$. También la voz acezar: "yuan con gran priesa, Saltando, y corriendo, y dançando, galopeando y aceçando" (L. II, f. 138v.), debe de haber tenido un mayor uso en el occidente peninsular, pues ya en época clásica son leoneses todos los autores que la emplean, con la excepción de Nebrija y del sevillano Hojeda, según el DCECH, y Autoridades comenta que no tiene uso alguno ${ }^{87}$. La carencia de información lexicográfica impide precisar el origen

$82 D C E C H$, la considera palabra viva en muchas partes, no ajena al castellano, y recoge la forma asturiana tochu. También Santamaría trae a colación una cita de Ramos que comenta que en gallego tocho es 'tosco, feo', y tochu, en asturiano, 'grosero, rústico'. En México, se recoge la acepción 'sucio, desaliñado', según Santamaría y Morínigo. Véase Franco Figueroa (2001).

${ }_{83}$ El DCECH comenta que Bluteau opone trasgo, nombre portugués, a duende, denominación castellana Los diccionarios generales de la lengua la recogen, no obstante, sin marcación.

84 El DCECH, s. v. clister, documenta la variante en Palencia y Nebrija, y comenta que hoy se usa en Canarias. Los demás diccionarios solo recogen clistel, y las variantes clister, o cristel. El CORDE [27-07-2011], con documentación de fines del XIV, en obras especializadas.

$85 D C E C H$, s. v. umbral. La voz se conserva también en Chile, con la variante, vulgar, lumbrar. Véase Franco Figueroa (2001).

${ }_{86} D C E C H$, s. v. ringlera. La forma rencle se documenta en Juan de Mena, rengle, en Fernández de Oviedo, Antonio de Guevara, y Góngora, en fragmento sayagués. La variante ringla, en la Pícara Justina, y, hoy, en el extremeño Gabriel y Galán, y en Cuba; y la forma rinclera, en asturiano. Neves registra una forma rengue 'tela ordinaria muy rala', en Cuba y Venezuela.

87 El $D C E C H$, que recuerda que es vocablo anticuado en toda España, al menos desde el siglo XVIII, y señala su vigencia en Cáceres, Salamanca, Tras os Montes, y en toda América, excepto en el centro y sur de Argentina. 
y uso tradicional de la voz enverrecado 'empecinado': "el muchacho desta edad, mal acondicionado, llora y encorájase, es encorajado y enberrecado" (L. X, f. 11r.), pero, de nuevo, hay que recordar que es vocablo registrado en el TLHA, con el significado 'gimotear', y con variantes se registra en el ALEICan, mientras que la Academia lo refiere a El Salvador, en la forma envarracarse, con el significado "enamorarse ciegamente' ${ }^{\text {'88 }}$.

Desde una perspectiva sincrónica, responden a este planteamiento vocablos como carne de membrillo: "mezcladas con carne de menbrillo o con qualqujera otra conSerua" (L. XI, f. 360v.), que el DCECH, s. v. membrillo, considera muy usual hoy en Andalucía; zarcillo: "también traýa çarcillos o orejeras" (L. X, f. 128v.-129r.); "ponjanle en las orejas vn ornamento como çerçillos de oro" (L. II, f. 86r.) que, en la acepción 'pendiente', se registra en toda Andalucía, según el TLHA. También las voces camellón: "los otros mantenjmjentos muy deSSeados y muy neceSsarios que eStán Sembrados y plantados en los camellones de la tierra" (L. VI, f. 35r.), y migajón: "otra manera de puchas hecha del migajón de las tortillas o de pan cozido" (L. VIII, f. 275r.), ambas no usuales para Moliner, y registradas en el TLHA, en Cádiz, Huelva, Málaga y Sevilla, con extensión de la primera a Granada, así como en el ALEICan son regionalismos actuales ${ }^{89}$.

\section{CONCLUSIONES}

El análisis léxico de la obra sahaguntina descubre no solo los usos propios del idiolecto de quien escribe, sino también la conciencia lingüística de esta diversidad diatópica, como sucede en otros escritores y lexicógrafos de los siglos XVI y XVII, que aprovechan en sus obras el bagaje léxico aprendido, con fines estilísticos o como recurso de aclaración, dentro de un marco cultural y estético que propicia la acumulación y la repetición de vocablos, con dobletes sinonímicos, a veces, de alcance regional. No obstante, el empleo reiterado de estos regionalismos, fundamentalmente aquellos de raigambre meridional, es prueba indiscutible del grado de nivelación léxica en la lengua del franciscano, y muestra como, en el proceso de criollización lingüística del español americano, la extensión diatópica y diastrática del 
vocabulario regional atiende a un proceso de adaptación determinado por la creación de la nueva sociedad colonial. La nueva geografía y los distintos modos de vida explican la presencia en América de voces antes privativas de áreas geográficas restringidas y las innovaciones semánticas que, en muchos casos, adquieren en el nuevo contexto. En este sentido, hay que recordar que del total de las voces consideradas dialectales, 56 son occidentalismos: abondar, acezar, achacarse, acucharrar, aferrar, alberque, añuzgarse, apañar, arrendar, aterecimiento, azcadillar o azcadilar, bilma, bocezar, calcaño, capillo, carrasco, cenizo y ceñilgo, chiflo, ciénaga y ciénega, collera, desainarse, embarazar, emprestar, enterriarse y enterriado, escarrapuzar y escarrapuzado, escogollarse, escriño, escupida, esfriarse, estilla, frangollado, frijol, gorolloso, horrura, lapa, llogar, monciña, mostolilla, páramo, pega, piño, prieto, recello, redruejo, renclera y rencle, sienso, silva, sobrado, tagarno, tocho, trasgo, trebejo y trebesino, trenchado, trípoda, vaquiruela, y zuñir; 15 términos pueden adscribirse al norte peninsular: buro, chamarra, cillero, cocote, correo, falso, granzón, lumbrar, muchila, puchas, recado, recaudo, soflar, tristel, verdasca; y 32 son palabras de empleo meridional: achocar, agro, altabaque, apregonar, arronjar, azotea, balandrón, brotón, camellón, camisa, candela, carne de membrillo, carrera, cernir, empolla, enverrecado, espadarte, espelucar y espelucado, esternudar, hiñir, injundia, migajón, ostión, plancha, poleadas, ponzancón, rancho, respelocado, tabardete, tamaño, torcaza, zarcillo, con lo que se comprueba la importancia de la impronta meridional en este trasvase léxico.

La adaptación y generalización de estas variantes geográficas en la nueva modalidad se comprueban en el número de voces que presentan un uso americano, confirmado en las obras lexicográficas actuales, con 25 de empleo panamericano: acezar, balandrón, camellón, candela, carrasco, ciénaga y ciénega, cenizo, chamarra, chiflo, cocote, collera, empolla, emprestar, espelucado, estilla, frangollado, frijol, páramo, prieto, rancho, recado, redruejo, sobrado, tamaño, torcaza; y 20 de ámbito regional: achocar, apañar, azotea, cernir, desainarse, escupida, esternudar, falso, granzón, lapa, lumbrar, ostión, piño, pucha, recaudo, refocilar, rencle y renclera, tabardete, tocho, zarcillo. Los nuevos sentidos que desarrollan estas voces se registran en 31 palabras: achocar, apañar, azotea, camellón, candela, carrasco, cenizo, cernir, chamarra, chiflo, collera, espelucado, falso, frangollado, frijol, granzón, lapa, páramo, piño, prieto, pucha, rancho, recado, recaudo, redruejo, refocilar, rencle y renclera, sobrado, tabardete, tocho, zarcillo.

En esta nómina de voces, procedentes de los distintos dialectos peninsulares, son abundantes, como no podía ser de otra manera, los términos relativos a la configuración física de las tierras, con voces como ciénega, 
lapa, o páramo, o aquellas que designan animales y plantas como ostión, torcaza, para la fauna, y carrasco, frijol, granzón, piño, redruejo, con referencia a la flora. También los elementos constitutivos de la arquitectura y las partes de una casa quedan representados en el corpus con términos como azotea, lumbrar, sobrado, y la designación de un caserío, con el andalucismo rancho. En el apartado de los enseres y utensilios aparecen registrados brujaca, cañizo, chiflo, collera, estilla, zarcillo. Para actividades de índole agrícola tenemos el término camellón. La alimentación está representada por pucha, la indumentaria, por chamarra. De nociones médicas encontramos empolla, escupida, tabardete. En el ámbito referido a cualidades podemos citar las voces balandrón, espelocado, falso, frangollado, prieto, tocho, y en lo que toca a las acciones de tipo general la lista la forman acezar, achocar, apañar, cernir, desainarse, emprestar, esternudar. Finalmente, aparte de estos campos semánticos, como voces que afectan a realidades variadas, presentamos candela, cocote, recado, recaudo, rencle y renclera.

\section{REFERENCIAS BIBLIOGRÁFICAS}

Alvar Ezquerra, Manuel. 2000. Tesoro léxico de las hablas andaluzas. Madrid: Arco/ Libros (THLA).

Barbolani, Cristina. 2003. Diálogo de la lengua, de Juan de Valdés. Madrid: Cátedra, $7^{\mathrm{a}}$ edición.

Bastardín CAndón, Teresa. 2005. Vitalidad de los términos indígenas en la Historia General de las Cosas de Nueva España de fray Bernardino de Sahagún. Cádiz: Servicio de Publicaciones de la Universidad de Cádiz [en línea].

2010. Variación léxica y uso discursivo en la Historia de Fray Bernardino de Sahagún. En M. ${ }^{\text {a }}$ Teresa Encinas Manterola et al. (coords.). Ars Longa. Diez años de AJIHLE. Buenos Aires: Voces del Sur, vol. II, pp. 803-820.

Buesa Oliver, Tomás. 1990. Problemas para la identificación del andalucismo léxico en el español de América. Actas de las VII Jornadas de Andalucía y América. Volumen II. Sevilla, pp. 270-282.

CÁrdenas, Gisela et Al. (coords.). 2000. Diccionario del español en Cuba. Español de CubaEspañol de España. Madrid: Gredos (EC).

Chuchuy, Claudio et al. (coords.). 2000. Diccionario del español en Argentina. Madrid: Gredos $(E A)$.

Corominas, Joan y José Antonio Pascual. 1980-1991: Diccionario crítico etimológico castellano e hispánico, 6 vols. Madrid: Gredos (DCECH).

Frago Gracia, Juan Antonio. 1994. Andaluz y español de América: historia de un parentesco lingüístico. Sevilla: Consejería de Obras Públicas y Medio Ambiente, Junta de Andalucía.

1995. La lengua de los castellanos-leoneses emigrados a Indias. La lengua española y su expansión en la época del Tratado de Tordesillas. Valladolid: Sociedad V Centenario del Tratado de Tordesillas, pp. 79-97. 
1998. Unidad y diversidad en el léxico español del Siglo de Oro. En César Hernández Alonso (ed.). Homenaje al profesor Emilio Alarcos Llorach en el centenario de su nacimiento. 1895-1995. Publicaciones de la Universidad-Junta de Castilla y León, pp. 71-90.

1999. Historia del español de América. Textos y contextos, Madrid: Gredos.

Franco Figueroa, Mariano. 2001. Meridionalismos en documentos hispanoamericanos (cartas particulares, la Historia General, de Sahagún, la Crónica y Buen Gobierno, de Guamán Poma de Ayala). Actas del V Congreso Internacional de El Español de América. Burgos: Universidad de Burgos.

Llorente Maldonado de Guevara, Antonio. 1984. Comentario de algunos aspectos del léxico del tomo I del ALEICan. Actas del II Simposio Internacional de Lengua Española, Gran Canaria: Excelentísimo Cabildo Insular de Gran Canaria, pp. 283-330.

Maldonado, Felipe C. R. 1995. Tesoro de la lengua castellana o española (1611), de Sebastián de Covarrubias. Edición facsímil. Madrid: Castalia. $2^{\mathrm{a}}$ edición corregida (Covarrubias).

Moliner, María. 1981. Diccionario de uso del español, 2 tomos. Madrid: Gredos.

Moreno de Alba, José G. 1992. Diferencias léxicas entre España y América. Madrid: Mapfre.

Morínigo, Marcos A. 1985. Diccionario de americanismos. Barcelona: Muchnik Editores, $2^{\mathrm{a}}$ edición.

Neves, Alfredo. 1975. Diccionario de Americanismos. Madrid: Sopena, $2^{\text {a }}$ edición.

Oesterreicher, Wulf. 2004. Textos entre inmediatez y distancia comunicativas. El problema de lo hablado escrito en el Siglo de Oro. En Rafael Cano Aguilar (coord.). Historia de la lengua española. Barcelona: Ariel, pp. 729-769.

Real Academia de La Lengua Española. 2001. Diccionario de la lengua española. Madrid: Espasa Calpe.

Banco de datos (CORDE) [en línea]. Corpus diacrónico del español [en línea]. Disponible en $<$ http://www.rae.es $>$.

- Nuevo Tesoro Lexicográfico de la Lengua Española (NTLLE) [en línea]. Disponible en $<$ http://www.rae.es $>$.

SAHAgún, Fray Bernardino DE. 1979. Códice Florentino. Historia general de las cosas de la Nueva España. Manuscrito 218-20 de la Colección Palatina de la Biblioteca mediceaLaurenziana. Edición Facsímil, 3 vols. México (Florencia): Casa editorial Giunti Barbèra. Archivo General de la Nación.

Sala, Marius et al. 1982. El español de América. Léxico, 2 vols. Bogotá: ICC.

Santamaría, Francisco De. 1983. Diccionario de mejicanismos. México: Editorial Porrúa. $4^{\text {a }}$ edición, corregida y aumentada.

Terreros y Pando, Esteban. 1786-1793. Diccionario castellano de las voces de ciencias y artes, I-II-III-IV. Madrid: Arco/Libros, edición facsímil, 1987.

VALDÉs, JuAn DE. 2003 [1737]. Diálogo de la lengua. Madrid: Cátedra. 